This is the author's manuscript for publication. The publisher-formatted version may be available through the publisher's web site or your institution's library.

\title{
Understanding online reading through the eyes of first and second language readers: an exploratory study
}

Haijun Kang

How to cite this manuscript

If you make reference to this version of the manuscript, use the following information:

Kang, H. (2014). Understanding online reading through the eyes of first and second language readers: An exploratory study. Retrieved from http://krex.ksu.edu

\section{Published Version Information}

Citation: Kang, H. (2014). Understanding online reading through the eyes of first and second language readers: An exploratory study. Computers \& Education, 73, 1-8.

Copyright: (c) 2013 Elsevier Ltd.

Digital Object Identifier (DOI): doi:10.1016/j.compedu.2013.12.005

Publisher's Link: http://www.sciencedirect.com/science/article/pii/S0360131513003291

This item was retrieved from the K-State Research Exchange (K-REx), the institutional repository of Kansas State University. K-REx is available at http://krex.ksu.edu 
Understanding online reading through the eyes of first and second language readers: An exploratory study

Haijun Kang

Department of Educational Leadership

Kansas State University

323 Bluemont Hall

1100 Mid-Campus Drive

Manhattan, KS 66506

\begin{abstract}
Utilizing eye-tracking technology and focusing on the "rapid”, "purposeful” and "comprehending" attributes of fluent reading, this study investigated first language (L1) and second language (L2) readers' online reading patterns and comprehension. Eye movement data from nine L1 readers and nine L2 readers were collected, analyzed and compared. Post-experiment interviews were conducted to obtain demographic and background information. The results indicate that L1 and L2 readers are heterogeneous when language proficiency is considered but they are homogeneous in many other aspects when the focus is on their online reading patterns and comprehension. While L1 readers read much faster than $\mathrm{L} 2$ readers, their attention distribution and performance on reading comprehension test are similar to L2 readers'. This study concludes that the essential online reading competency factors are similar in L1 and L2's online reading when the "rapid", "purposeful" and "comprehending" attributes of fluent reading are under investigation. When the core vocabulary of a language is mastered, it is metacognitive reading skills that play a major role in fluent reading in the context of new literacy.
\end{abstract}

\title{
Key words
}

Online reading pattern; online reading comprehension; eye movement; first language reader (L1); second language reader (L2)

\section{Introduction}

Because of the advent of the Internet and Information Communication Technologies (ICTs), today's knowledge and information are frequently presented, distributed, received and decoded in hypertext format. This development trend has greatly challenged traditional literacy research and practices because hypertext offers the opportunity to process information in nonlinear and multiple formats (Slaouti, 2002). These features of hypertext make reading online a very elective process and makes online reading "a selfconscious act of creating knowledge from a variety of sources" (Landow, as cited in 
Warschauer, 1999, Reading/Research section, para.2). Mastering new literacy skills, strategies and dispositions, hence, become the necessity for today's readers to succeed in their online reading activities. As said by Leu et al. (2004), “comprehension processes, decoding processes, and what 'counts' as literacy activities must change to reflect readers' and authors' present-day strategies for comprehension and response” (p.1572).

A growing body of literature investigates the differences between conventional literacy and new literacy activities, dispositions of new literacy (Leu et al., 2004), online reading skills and strategies (Chang, 2005; Singhal, 1999), factors affecting reading comprehension (Warschauer, 1999), among others. Given the shifting literacy experience, second language education needs to respond accordingly. It is not wise to rely on old techniques for developing second language education. Nor should we assume that same models exist across old/new literacy divide. While many literacy studies indicate the benefit of cross-referencing literacy research on first language (L1) and second language (L2) readers to understand new literacy phenomenon (Grabe, 1991), there is a dearth of empirical studies specifically designed to compare L1 and L2 readers' new literacy in general and their online reading patterns and comprehension in particular.

The purpose of this study was, therefore, to compare L1 and L2 readers' online reading patterns and comprehension to better understand "fluent reading" (Grabe, 1991) in the context of new literacy. According to Grabe (1991), "fluent reading is rapid, purposeful, interactive, comprehending, flexible, and gradually developing” (p.378). These six attributes of fluent reading encompass different components of reading literacy. "Rapid", "purposeful” and "comprehending" emphasize reading efficiency and effectiveness; "Interactive", "flexible" and "gradually developing" call for attention to concrete and ever-changing reading activities and strategies. Because of the lack of research on online reading efficiency and effectiveness, as noted in the literature review below, we developed the following three research questions to specifically address online reading efficiency and effectiveness:

- "Rapid” - How fast can L1 and L2 readers read?

- "Purposeful” - What do L1 and L2 readers read and how much do they read?

- "Comprehending” - How well do L1 and L2 readers perform on reading comprehension test?

\section{Literature Review}

\subsection{Conventional Reading Practices and Research}

According to Grabe (1991), "the reader has a purpose for reading, whether it is for entertainment, information, research, and so on. ... The reader typically expects to understand what s/he is reading” (p. 378). However, reading comprehension is a very complex cognitive activity, "a process of making meaning from the text” (Woolley, 2011, p. 15). Reading comprehension comprises of three major operations including the decoding of lexical information, extraction of ideas, and construction of new meaning (Koda, 2005, 2010). While Koda thinks that the decoding process is especially critical and challenging to L2 readers because of their limited linguistic knowledge (2005), other 
researchers have found the other two processes are equally important to L2 readers' reading comprehension (Akyel \& Ercetin, 2009; Dommes, Chevalier \& Lia, 2011; Hill et al., 2011; Huang et al., 2009; Maarof \& Yaacob, 2011; Mayer, 1997; Park \& Kim, 2011; Yang, 2010).

Koda (2010) attributes these various perspectives to L2 reading comprehension to "three implicit assumptions" that underlie most research studies and conventional foreign language learning practices. These three assumptions are "(1) L2 reading skills develop automatically as a by-product of increased L2 linguistic knowledge; (2) linguistic knowledge can be learned through explanation and memorization; and therefore, (3) L2 reading fluency can be achieved through explicit instruction on grammar and vocabulary" (p. 6). Based on the examination of each assumption, Koda (2010) suggests that future research studies focus on improving mapping skills, enhancing text-based inference skills and promoting knowledge incorporation skills.

\subsection{Online Reading Practices and Research}

Because of the capacity to create in-text hyperlinks to other resources such as images, videos, audios and other texts, Internet has empowered readers by giving them various options of comprehending online reading. This, by no means, simplifies reading comprehension process. On the contrary, the non-linear structure of online text is providing both challenges and promises to the reader and requires special skills, strategies, and dispositions (Coiro et al., 2008; Huang, 2012; Leu et al., 2007). Castek et al. (2011), believe that "five processing practices are required when reading on the Internet: (a) reading to construct useful questions; (b) reading to locate information; (c) reading to evaluate information critically; (d) reading to synthesize information and (e) reading and writing to communicate information” (p.95).

Many studies are done researching the promises and challenges that the delivery of reading in online and electronic format has offered. Castel et al. (2011) found out that some of those students who do not do well with offline reading surprisingly read well in online learning environment. They attribute this to many new features made available by putting reading materials online. For example, most online content is searchable, the hyperlinks to additional resources break down the difficulty level of online reading, the add-on of multimedia feature satisfies different readers' reading styles, and organizational tools such as bookmarking make it easy to manage and access multiple resources through a couple clicks. Mayer (1997) reviewed eight studies in which research participants received learning information presented in different hyper- and multi-media formats. Their study revealed that readers' online reading patterns were non-linear and multiple. They also noticed that those who had little prior knowledge or who had high spatial ability benefited the most from the non-linear feature of online reading. Akyel and Ercetin (2009) attributed this to those readers' abilities to use annotations or navigation functions available through online reading to compensate for their lack of prior knowledge. Park and Kim's study of L2 readers' online reading pattern (2011) indicated that L2 learners dialogued with themselves, others, multiple resources and texts simultaneously. Their research participants reported that videos and pictures were helpful to their reading comprehension, text was still important, but audios were found not useful 
dues to the lack of visual cues. Foltz's (1993) study on readers' comprehension and strategies in both linear- and hyper-text indicated that more fluent online readers tended to be more heuristic in online reading environment.

\subsection{Reading strategies and impact factors}

There is a wealth of studies on reading strategies in both online and offline reading environments. Huang et al. (2009) reviewed research studies on L2 readers’ reading strategies and developed a reading strategy typology that put most commonly used reading strategies into two categories, namely "top-down” and "bottom-up” strategies. Strategies such as general or global reading strategies are labeled as "top-down" approach that the reader uses to "predict text content, construct a goal for reading, and self-monitor the reading process" (p.14); strategies such as local, problem-solving and support strategies are treated as "bottom-up" approach that the reader uses to "understand specific linguistic units” (p.14). Akyel and Ercetin's study (2009) indicated that the "top-down” approach is an important strategy to online reading because of the non-linear nature of online reading structure and that the reader needs to be more responsible to their own reading processes. Park and Kim’s study (2011) added a socio-cultural lens to our understanding of online reading by arguing that dialogue is an important reading strategy because interacting with the object and the context is a human nature and that their research participants dialogued with themselves, with others, and with online resources throughout their whole reading processes. Some new reading strategies unique to online reading were identified as well, including hypermedia reading, the use of computer accessories, the use of annotations and navigation (Akyel \& Ercetin, 2009; Huang, 2012; Huang et al., 2009; Park \& Kim, 2011; Sakar \& Ercetin, 2005). It is also indicated that online readers tend to transfer the reading strategies they already have from one medium to another (Akyel \& Ercetin, 2009; Elshair, 2002; Foltz, 1993; Huang, 2012).

There are many factors that affect readers' selection of reading strategies. Language proficiency, for example, determines how readers with different language proficiency choose between "top-down" and "bottom-up" strategies. Fluent language readers tend to use "top-down” strategies more frequently (Chang, 2005; Huang, 2012). Fluent readers often employ more strategies and frequently switch between strategies to find the most appropriate one or ones to tackle given reading tasks and this is applicable to both L1 and L2 readers (Maarof \& Yaacob, 2011; Yang, 2010). Topic knowledge or prior knowledge affects reading strategies as well. Akyel and Ercetin's (2009) study revealed that readers with more prior knowledge used more cognitive and metacognitive strategies than those with less topic knowledge. Readers with more prior knowledge tend to be flexible with the use of different reading strategies and are not constrained by the prescribed reading structure. Their reading process is very selective and is based on how much they know about the subject and what their interests are. Their reading patterns, therefore, are not as coherent as those with less prior knowledge (Salmeron, Kintsch, \& Canas, 2006). Other factors identified to affect online reading comprehension include readers cognitive flexibility (Dommes et al, 2011), visual aesthetics (Norman, 2004; Tractinsky et al., 2006), computer experience (Hill et al, 2011), perceptions of website interface and media richness (Chen et al, 2011), preference of reading delivery mode (Vandelanotte et al., 
2012), previous online reading experiences (Huang, 2012), contextual factors, and readers' personal characteristics (Adesope et al., 2011).

Two major themes emerged from the literature review. First, the majority of studies on online and offline reading literacies focus mainly on the "interactive”, "flexible”, and "gradually developing” attributes of fluent reading (Grabe, 1991). This group of studies examined how learners interacted and dialoged with the object, context and resources; how learners employed different reading strategies in different reading environments; and how learners needed to be diligent as the development of fluent reading skills is a longterm effort and commitment. The "rapid”, "purposeful” and "comprehending” attributes of fluent reading, however, have yet gained enough attention. Fluent reading is a complex and integrated cognitive process and the six attributes of fluent reading are tightly intertwined with each other. A study of these three less-researched attributes of fluent reading should greatly contribute to our understanding of online readers' reading patterns and comprehensions. Second, most studies used either L1 or L2 readers as their only research participants and few studies have included both L1 and L2 reader populations to do comparative research. This study engages these two themes by employing a comparative approach to examining online reading efficiency and effectiveness of both L1 and L2 readers in the context of new literacy.

\section{Research Design}

Equal number of American readers and Chinese readers were recruited to participate in this study. Because the reading material was written in English, the American participant group was labeled as L1 reader group, and the Chinese participant group was labeled as L2 reader group. Both groups were given the same reading material and were asked to complete the same reading comprehension test at the end. The reading was an introduction of The Transactional Distance Theory developed by Michael Moore in the early 1970s (Kang \& Gyorke, 2008).

As hypertext increases reader's cognitive load that inevitably influences reading comprehension (DeStefano \& LeFevre, 2007), a combination of linear and hierarchical hypertexts were developed to accommodate different reading styles and preferences so as to help alleviate possible increase of cognitive load (See Fig. 1. Sample reading page). "Previous Page" and "Next Page" links were created at the bottom of each page so that research participants didn't need to sequence their reading if they didn't want to. Scaffolding and chunking techniques were used to aid in overcoming memory load (Sutherland-Smith, 2002; Yang, 2001). A breadcrumb navigation bar was created at the top of each page to give research participants the option of sequencing their own reading by navigating between the seven subtopics.

After the reading, participants were asked to complete a reading comprehension test. The reading comprehension test was composed of 5 questions that test both higher- and lower-level reading comprehension skills (Cohen, 1994). Three questions were created to test research participants' recall of main ideas (higher-level reading comprehension) and two questions were used to test research participants' recall of details (lower-level reading comprehension). To mimic the real-world online learning environment, both the 
reading material and reading comprehension test were stored and delivered in an online Learning Management System.

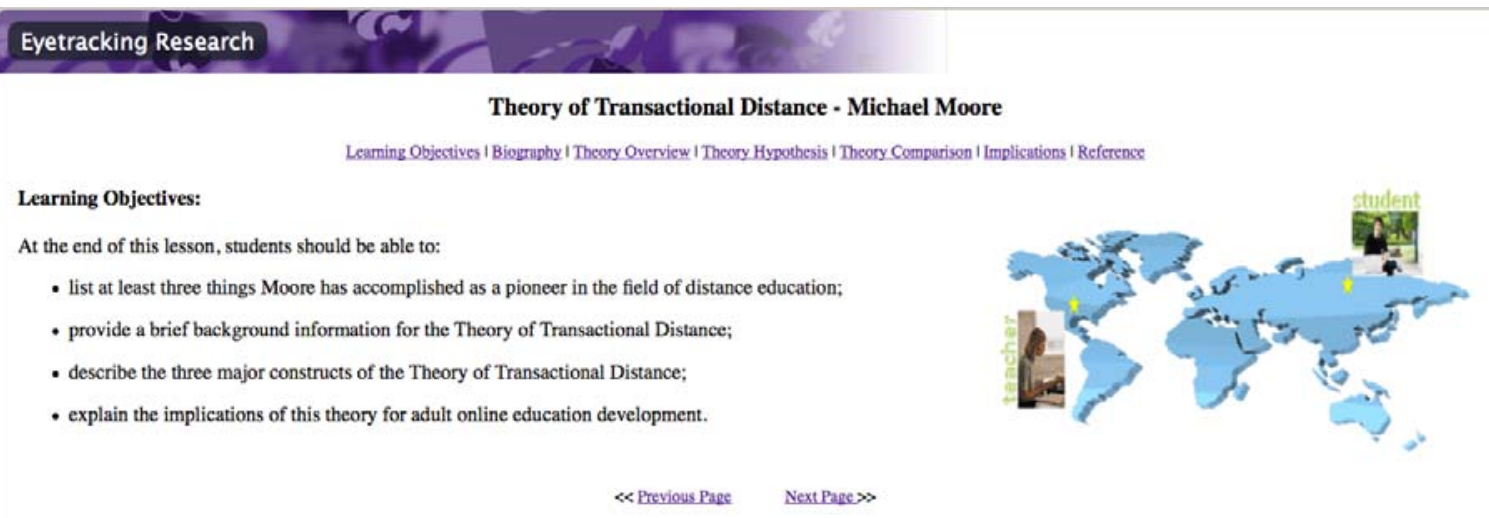

Fig. 1. Sample reading page

\subsection{Participants}

In this study, purposive sampling was employed to select equal number of L1 and L2 participants. An invitation email was sent out to a graduate student email listserv indicating that we were looking for a number of L1 and L2 graduate students for a paid research study. Because this email listserv was managed by the continuing education unit of a midwestern higher education institution in the U.S., the members of this listserv were mainly graduate students who were enrolled in one or more online or hybrid courses. In our invitation email, we also asked those interested in our study to self-identify whether they were native English speakers or not so that we could recruit equal number of L1 and L2 participants. As a result, 18 research participants were recruited. Half of them selfidentified as L1 readers whose mother language was English and the other half selfidentified as L2 readers who finished undergraduate education in their home countries and came to the U.S. to pursue masters or doctoral studies. The participant age range was from 27 to 59 years, with a mean age of 33.7 years ( $S D=7.92)$. Female participants comprised $66.7 \%$ of the sample and male participants $33.3 \%$. $88.9 \%$ of the sample received a bachelor or higher degree. Research participants received monetary compensation for their participation in this study.

\subsection{Data Collection Tools and Procedures}

A brief survey was used to collect demographic data including age, gender, ethnicity, education, and employment status. It was administered to the research participants upon their arrival at the research site. An interview was conducted after research participants finished their reading tasks. The interview was to assess (1) research participants' topic knowledge (prior knowledge on the assigned reading topic), (2) their experience of using Internet in their everyday life, (3) their online reading and learning experiences, and (4) their overall experience with the reading tasks designed for this study.

Tobii T60 eyetracker was used to track research participants' eye movements and Attention Tool 4.9 was used to store and analyze eye movement data. Each reading page 
mentioned above was created as a stimulus and eleven stimuli in total were created to collect eye movement data. After completing a short demographic survey upon arrival, the research participants were calibrated to the eyetracker and directed to the first stimulus - "Learning Objectives" page. From that point on, it was left to the research participants to decide whether to use the "Previous Page" and "Next Page" links or the breadcrumb navigation bar to navigate through the eleven stimuli. Research participants' exposures to each stimulus were recorded and stored in Attention Tool 4.9 and their eye gaze paths for the entire duration of the exposure time were replayed back to research participants when they were asked to describe their experience with the assigned online reading tasks. The purpose of reviewing eye gaze paths together with the research participants was to further understand their cognitive processes by inviting them to play the role of a co-researcher in the analysis of their own cognitive reading processes.

\section{Results}

The findings from data analysis showed more commonalities than differences between L1 and L2 reader groups. The self-reports of topic knowledge from L1 and L2 participants confirmed that none of them had prior knowledge on the selected online reading topic before participating this study. This helped to control the impact of prior knowledge on their reading processes and their performance on the comprehension test because content schemata has been considered as a major factor affecting reading comprehension (Anderson \& Pearson, 1984; Wilson \& Anderson, 1986). These participants self-identified themselves as moderate to advanced Internet users and all had some level of online learning experiences ranging from doing some required online readings for hybrid learning classes to taking courses completely online. Other than different language proficiency levels (L1 vs. L2) and participants' own metacognitive reading skills that were under investigation, no other factors that might provide alternative explanation on the research participants' online reading patterns and comprehension were found.

\subsection{Reading Comprehension Test}

Table 1 shows the reading comprehension test results. As said earlier, the reading comprehension test was composed of five questions. Three questions were used to test research participants' higher-level reading comprehension and two questions were used to test research participants lower-level reading comprehension.

Table 1

Reading Comprehension Test Results

\begin{tabular}{|l|l|l|l|l|l|}
\hline $\begin{array}{l}\text { Participant } \\
\text { Group }\end{array}$ & Q 1 (Detail) & $\begin{array}{l}\text { Q 2 (Main } \\
\text { idea) }\end{array}$ & $\begin{array}{l}\text { Q 3 } \\
\text { (Detail) }\end{array}$ & $\begin{array}{l}\text { Q 4 (Main } \\
\text { idea) }\end{array}$ & $\begin{array}{l}\text { Q 5 (Main } \\
\text { idea) }\end{array}$ \\
\hline $\begin{array}{l}\text { L1 reader } \\
\text { group }\end{array}$ & 6 correct & $\begin{array}{l}\text { 8 correct } \\
1 \text { wrong }\end{array}$ & $\begin{array}{l}3 \text { correct } \\
6 \text { wrong }\end{array}$ & $\begin{array}{l}\text { 2 correct } \\
7 \text { wrong }\end{array}$ & $\begin{array}{l}9 \text { correct } \\
0 \text { wrong }\end{array}$ \\
\hline $\begin{array}{l}\text { L 2 learner } \\
\text { group }\end{array}$ & 7 correct & 9 correct & 6 correct & 2 correct & 9 correct \\
2 wrong & 0 wrong & 3 wrong & 7 wrong & 0 wrong \\
\hline
\end{tabular}


A t-test was conducted to further compare the reading comprehension test scores of both L1 and L2 reader groups. There did not exist any significant differences in the reading comprehension test scores of both $\mathrm{L} 1$ readers $(\mathrm{M}=3.11, \mathrm{SD}=1.17)$ and $\mathrm{L} 2$ readers $(\mathrm{M}=3.67), \mathrm{SD}=1) ; \mathrm{t}(16)=1.09, \mathrm{p}=0.29(>0.05)$. These results suggest that $\mathrm{L} 1$ and $\mathrm{L} 2$ readers participated this study performed equally well on the reading comprehension test regardless of the fact that English is the native language for L1 group and second language for L2 group.

It is interesting to see that the test result pattern for Q3 was completely opposite across L1 and L2 groups. Q3 asked for the year the theory was first published and it was the only question that included numerical numbers in answer options. Could this be the reason why the test result pattern for Q3 came out opposite? Does it mean that our L1 participants were less sensitive to numerical numbers than our L2 participants? Finding no literature talking about a connection between the inclusion of numerical numbers in reading comprehension test and test takers' performance, we did not include enough questions with numerical numbers embedded to help us validate this finding. Hence, a separate research is suggested to further verify this finding.

\subsection{How $L 1$ and $L 2$ readers read online}

A series of analysis, including the analysis of (1) What L1 and L2 readers read, (2) How much content they read, (3) How fast they located answer cues, and (4) How much time they spent on each stimulus, were conducted to understand how L1 and L2 readers processed and comprehended information online.

\subsubsection{What $\mathrm{L} 1$ and $\mathrm{L} 2$ readers read}

To find out what L1 and L2 readers read, we needed to understand research participants' attention distribution. Tobii T60 eyetracker was used to calculate research participants' eye fixations (gaze durations) and frequencies and then present them in the form of heatmap. Heatmap shows the distribution of attention illustrated using attention points and gaze sequence of the total target group (iMotions, 2013). Therefore, technically speaking, where research participants spend time reading or paying attention to will be shaded in different colors to show different levels of attention intensity.

Figure 2 is an example illustration of our research participants' attention distribution on one reading stimulus. It indicates that L1 and L2 readers' attention distributions were similar on this stimulus. Our comparison of the heatmaps drawn on all eleven stimuli yielded the same result that there were no significant differences found between L1 and L2 readers' attention distributions or eye gaze patterns. 


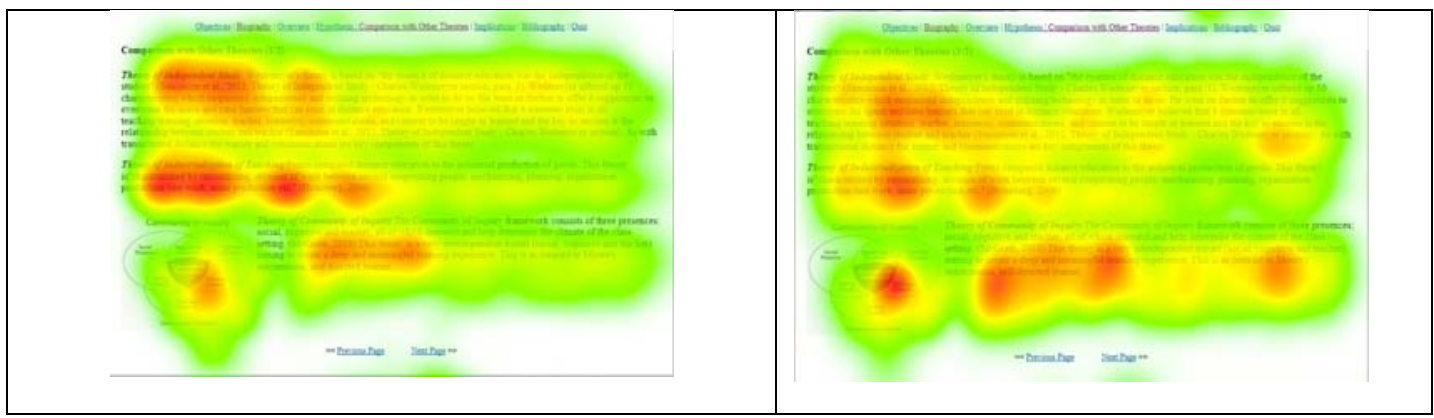

Fig. 2. Heatmap Comparison (Stimulus 5 - Theory Comparison) (Left: L1 readers; Right: L2 readers) (Blue = low attention intensity; Yellow = moderate attention intensity; Red = high attention intensity)

\subsubsection{How much content $\mathrm{L} 1$ and $\mathrm{L} 2$ readers read}

To further validate the findings on the overall reading attention distribution, reading meter analysis was conducted. Reading meter analysis reveals the amount of text that was read for any selected text area in a stimulus (iMotions, 2013). As shown in Table 2, the analysis yielded the same result that L1 and L2 readers' reading attention distributions were similar and no significant differences were found.

Table 2

Reading Meter Analysis (Unit: \%)

\begin{tabular}{|l|l|l|l|l|l|}
\hline Participants & $\begin{array}{l}\text { Stimulus 1 } \\
\mathrm{M}(\mathrm{SD})\end{array}$ & $\begin{array}{l}\text { Stimulus 2 } \\
\mathrm{M}(\mathrm{SD})\end{array}$ & $\begin{array}{l}\text { Stimulus 3 } \\
\mathrm{M}(\mathrm{SD})\end{array}$ & $\begin{array}{l}\text { Stimulus 4 } \\
\mathrm{M}(\mathrm{SD})\end{array}$ & $\begin{array}{l}\text { Stimulus 5 } \\
\mathrm{M}(\mathrm{SD})\end{array}$ \\
\hline $\begin{array}{l}\text { L1 reader } \\
\text { group }\end{array}$ & $80(15.26)$ & $80(10.31)$ & $70(18.08)$ & $80(19.09)$ & $80(15.26)$ \\
\hline $\begin{array}{l}\text { L2 reader } \\
\text { group }\end{array}$ & $70(12.36)$ & $80(11.29)$ & $70(15.23)$ & $70(27.61)$ & $70(13.00)$ \\
\hline
\end{tabular}

\subsubsection{How fast $L 1$ and $L 2$ readers located answer cues}

To pass the reading comprehension test, research participants needed to locate answer cues to all the five reading questions. To find out how fast L1 and L2 readers located the answer cues, an Area of Interest (AOI) analysis was conducted. AOI analysis enables the selection of any area in a stimulus to reveal the attention using same measurement as heatmap (iMotions, 2013). TTFF is the Time to First Fixation value generated by AOI analysis. It tells when a participant's eye is fixed on an answer cue the first time. As shown in Table 3, it took L2 readers $42.7 \mathrm{~s}$ on average to locate an answer cue. That is twice as much as the time L1 readers spent (average: $21.76 \mathrm{~s}$ ). The nature of the answer cues, whether for main ideas or for details, had no effect on the time spent. Therefore, L2 readers show a propensity for slower viewing.

Table 3

TTFF Analysis Comparison (Unit: Second)

\begin{tabular}{|l|l|l|l|l|l|}
\hline Participants & Cue 1 & Cue 2 & Cue 3 & Cue 4 (Main & Cue 5 \\
\hline
\end{tabular}




\begin{tabular}{|l|l|l|l|l|l|}
\hline & $\begin{array}{l}\text { (Detail) M } \\
\text { (SD) }\end{array}$ & $\begin{array}{l}\text { (Main idea) } \\
\text { M (SD) }\end{array}$ & $\begin{array}{l}\text { (Detail) M } \\
\text { (SD) }\end{array}$ & $\begin{array}{l}\text { idea) M } \\
\text { (SD) }\end{array}$ & $\begin{array}{l}\text { (Main idea) } \\
\text { M (SD) }\end{array}$ \\
\hline $\begin{array}{l}\text { L1 reader } \\
\text { group }\end{array}$ & $14.7(5.33)$ & $3.7(1.54)$ & $3.4(1.28)$ & $14.6(7.25)$ & $72.4(13.95)$ \\
\hline $\begin{array}{l}\text { L2 reader } \\
\text { group }\end{array}$ & $49.8(13.00)$ & $31.2(14.17)$ & $6.7(2.87)$ & $22.5(9.52)$ & $\begin{array}{l}103.3 \\
(29.32)\end{array}$ \\
\hline
\end{tabular}

\subsubsection{How much time $\mathrm{L} 1$ and $\mathrm{L} 2$ readers spent on each stimulus}

An analysis of the amount of time a participant spent on each stimulus, Average Exposure Time (AET), was conducted as well. AET analysis provides a qualitative overview of the respondent data for each stimulus (iMotions, 2013). Table 4 indicates that L2 reader group spent on average $177.92 \mathrm{~s}$ on each stimulus. That is $62 \%$ more than the average time (110.1 s) L1 reader group used. Therefore, L2 reader group shows a propensity for longer times used to digest information.

Table 4

AET Analysis (Unit: Second)

\begin{tabular}{|l|l|l|l|l|l|}
\hline Participants & $\begin{array}{l}\text { Stimulus 1 } \\
\text { AET M } \\
(\text { SD) }\end{array}$ & $\begin{array}{l}\text { Stimulus 2 } \\
\text { AET M } \\
(\text { SD) }\end{array}$ & $\begin{array}{l}\text { Stimulus 3 } \\
\text { AET M } \\
(\text { SD) }\end{array}$ & $\begin{array}{l}\text { Stimulus 4 } \\
\text { AET M } \\
(\text { SD) }\end{array}$ & $\begin{array}{l}\text { Stimulus 5 } \\
\text { AET M } \\
(\text { SD) }\end{array}$ \\
\hline $\begin{array}{l}\text { L1 reader } \\
\text { group }\end{array}$ & 126.4 & 120.8 & 61.5 & 114.2 & 127.6 \\
\hline $\begin{array}{l}\text { L2 reader } \\
\text { group }\end{array}$ & $(25.12)$ & $(32.19)$ & $(19.43)$ & $(30.21)$ & $(22.14)$ \\
\hline
\end{tabular}

\subsubsection{How $L 1$ and $L 2$ readers navigated through the reading}

To help alleviate possible increase of cognitive load because of the use of hypertext, a combination of linear and hierarchical hypertexts were created. Data analysis indicated that the hierarchical hypertext structure was not considered as valuable as the linear structure. Most participants mainly used the "Previous Page" "Next Page" buttons to navigate. The breadcrumb navigation bar was the least used interface element. While being asked why they didn't use the breadcrumb navigation bar, most interviewees said that it was easier to use the "Previous Page" "Next Page" buttons to navigate. Doing so, they did not need to worry about missing important information.

\section{Discussion}

The results of this study indicate that the L1 and L2 reader groups are heterogeneous when language proficiency is considered (native English speaker vs. English as a secondary language speaker) but they are homogeneous in many other aspects when the focus is online reading patterns and comprehension. This research concurs with Eskey's 
argument (2005) that the essential online reading competency factors are similar in L1 and L2 reading. When basic language proficiency is reached or the core vocabulary is mastered, it is metacognitive reading skills that make one a fluent reader. The results will be discussed around the three research questions under investigation.

\section{1. “Rapid” - How fast can $L 1$ and $L 2$ readers read?}

According to Grabe (1991), "The reader needs to maintain the flow of information at a sufficient rate to make connections and inferences vital to comprehension" (p. 378). In this study, L1 readers read much faster than L2 readers. L1 readers were able to find answer cues in $21.76 \mathrm{~s}$ while it took L2 readers twice as much times; L1 readers spent on average $110.1 \mathrm{~s}$ on each stimuli page while L2 readers spent $62 \%$ more times. The results make it obvious that L1 readers read at about twice the speed as L2 readers. But this by itself is not enough to put L1 readers into Grabe's fluent reader category. Grabe didn't specify the "sufficient rate" that is vital to reading comprehension. Our reading comprehension test results seem to indicate that there is no absolute causal relationship between reading speed and comprehension. L1 readers in this study might sample the visual symbols on each stimuli page faster and used fewer resources as indicated by Stanovich (1991). But that might be because of the fact that L1 readers in this study had much larger vocabulary and could identify the vast majority of words automatically. This might also mean that L1 readers used general strategies or global strategies frequently while L2 readers attended to local strategies (Huang et al., 2009).

\section{2. "Purposeful" - What do L1 and L2 readers read and how much do they read?}

People read for a purpose but they don't read in a letter-by-letter, word-by-word manner whether it's online or offline. Their reading is always a selective process (Goodman, 1967). This research not only supports this point of view but also extends to online reading in second language. The heatmap analysis above shows that what L1 readers found useful to understanding the assigned reading were also found meaningful by L2 readers. The analysis of the answer-cue embedded text areas indicates that both L1 and L2 readers read about $70-80 \%$ of the selected texts. This result is consistent with the findings from other eyetracking research studies in the area of reading literacy, such as Carpenter \& Just (1986) and Rayner \& Pollatsek (1989). It is, therefore, reasonable to assume that language is no longer the major contributor to online reading comprehension after the reader possesses the basic language proficiency or core vocabulary. Further, because research participants in both L1 and L2 reading groups all had no prior topic knowledge, all were used to using Internet to search for information, and all had some online learning experiences, it seems that metacognitive skills that L1 and L2 readers brought with them played a major role in their reading comprehension. This concurs with Smith (1982) that the reader contributes more than do the reading itself when reading comprehension is under investigation. 


\section{3. “Comprehending” - How well do $\mathrm{L} 1$ and $\mathrm{L} 2$ readers perform on reading comprehension test?}

It is common sense that when we read we expect to understand what we are reading. How much we can comprehend varies depending on many known and unknown factors as indicated in the literature review. In this study, no matter how much L1 and L2 readers read, what they read, and how fast they read, both reader groups performed equally well on the reading comprehension test at both higher and lower reading comprehension levels.

However, our interviews and L2 readers' slower reading speed revealed that there exists a "bottleneck" in L2 readers' reading comprehension and we need to separate "readingbased comprehension problems" from "language-based comprehension difficulties" if to find better solutions to new literacy (Zoghi et al., 2010). Many L2 readers participated in this study indicated that they were familiar with most of the vocabulary used in the reading but had difficult time integrating ideas grasped at word- and sentence-level to achieve global text coherence (Bernhardt, 1991; Catts, Adlof, \& Weismer, 2006; Yuill \& Oakhill, 1991). This supports the argument Cain et al, (2001), Cromer (1968), and Miller (1965) made that the meaning of a sentence is not a linear sum of the meanings of the words that comprise it. Research participants also indicated that they adopted paper-based text reading skills and strategies to online reading instinctively, which is consistent with Park and Kim’s (2011) findings.

In addition, most L1 and L2 readers in this study reported that they didn't find the hierarchical structure useful whether to help them speed up their reading process, locate important information, or improve their reading comprehension. On the contrary, several participants expressed the concern that the use of the breadcrumb navigation bar might make them miss important information and that's why they chose to use the "Previous Page" and "Next Page" links to navigate. So, it seems that the participants were willing to take on the challenge of possible increased cognitive load and adjust their reading styles and preferences to accommodate the assigned reading tasks.

\section{Conclusion}

About two decades ago, Grabe (1991) asserted that "reading is probably the most important skills for second language learners in academic contexts” (p. 375). He further specified that "fluent reading is rapid, purposeful, interactive, comprehending, flexible, and gradually developing” (p.378). In the advent of new literacy, his assertion not only still holds the truth in L2 reading but is also applicable to L1 reading in online and electronic formats. Taking an exploratory approach and focusing on online reading efficiency and effectiveness, we tracked L1 and L2 readers' eye movements to gain better understanding of the "rapid”, "purposeful” and "comprehending” aspects of fluent reading (Grabe, 1991) in the context of new literacy. The empirical results indicate that it is the reader's metacognitive reading skills that matter when the core vocabulary is mastered and the "rapid", "purposeful” and "comprehending” attributes of fluent reading are under investigation. Helping students employ and practice appropriate metacognitive 
reading skills and strategies is beneficial in making our students fluent readers whether they do their online reading in first language or second language.

\section{Limitations and Future Research}

Although techniques such as eyetracking were used to reduce subjective input from both the researcher and research participants, this study was limited by the relatively small sample size. For example, given that we had 9 participants in each group and 5 items on the reading comprehension test, the conclusion made based on Table 1 that "L1 and L2 readers participated this study performed equally well on the reading comprehension test" was not statistically solid. Future research to further test this hypothesis with a much larger sample size is needed. The question of why the test result pattern for Q3 turned out to be completely opposite across L1 and L2 groups is worthy of further exploration as well. Like other research studies, the findings presented in this research should not be considered as conclusive. The reader is reminded to carefully consider the restrictions placed on the data analysis by the relatively small number of participants. Future researchers are encouraged to utilize other statistical methods and measures to either extend on or verify the findings of this study.

Future research is also encouraged to explore the questions identified through this study, including: (1) Is there any causal relationship between reading speed and reading comprehension? (2) Do L1 readers employ general or global strategies more frequently than L2 readers and L2 readers prefer local strategies when comprehending online reading in second language? (3) Is it true that metacognitive skills play a more important role in reading comprehension than language skills when the core vocabulary of a language is mastered? (4) Why are readers willing to take on the challenge of possible increased cognitive load and compromise their own reading styles and preferences to

accommodate assigned reading tasks even though doing so makes reading less efficient?

\section{Acknowledgements}

The author thanks iMotion for their generous lending of a Tobii T60 eyetracker and the Attention Tool 4.9 software for this research.

\section{Reference}

Adesope, O. O., Lavin, T., Thompson, T., \& Ungerleider, C. (2011). Pedagogical strategies for teaching literacy to ESL immigrant students: A meta-analysis. British Journal of Educational Psychology, 81, 629-653.

Akyel, A., \& Ercetin, G. (2009). Hypermedia reading strategies employed by advanced learners of English. System, 37(1), 136 -152.

Anderson, R. C., \& Pearson, P. D. (1984). A schema-theoretic view of basic processes in 
reading comprehension. In P. D. Pearson, R. Barr, M. L. Kamil, \& P. Mosenthal (Eds.), The handbook of reading research (pp. 255-292). New York, NY: Longman. Bernhardt, E. B. (1991). Reading development in a second language. Norwood, NJ: Ablex.

Cain, K., Oakhill, J. V., Barnes, M. A., \& Bryant, P. E. (2001). Comprehension skill, inference making ability, and their relation to knowledge. Memory \& Cognition, 29, 850-859.

Carpenter, P., \& Just, M. (1986). Cognitive processes in reading. In J. Orasanu (Ed.) Reading comprehension: From theory to practice (pp. 11-29). Hillsdale, NJ: Lawrence Erlbaum.

Castek, J., Zawilinski, L., McVerry, G., O'Byrne, I., \& Leu, D. J. (2011). The new literacies of online reading comprehension: New opportunities and challenges for students with learning difficulties. In C. Wyatt-Smith, J. Elkins, \& S. Gunn (Eds.) Multiple perspectives on difficulties in learning literacy and numeracy (pp. 91-110). New York, NY: Springer.

Catts, H. W., Adlof, S. M., \& Weismer, S. E. (2006). Language deficits in poor comprehenders: A case for the simple view of reading. Journal of Speech, Language, and Hearing, 49(2), 278-294.

Chang, M. (2005). Instructional strategy application in Web-based language teaching and learning. Taipei: Crane Publishing Company.

Chen, J., Linnk, C., Yen, D., \& Linn, K. (2011). The interaction effects of familiarity, breadth and media usage on web browsing experience. Computers in Human Behavior, 27(6), 2141-2152.

Cohen, A. (1994). Assessing language ability in the classroom. Boston, MA: Heinle \& Heinle Publishers.

Coiro, J., Knobel, M., Lankshear, C., \& Leu, D. J. (2008). Central issues in new literacies and new literacies research. In J. Coiro, M. Knobel, C. Lankshear, \& D. J. Leu (Eds.), The handbook of research in new literacies (pp. 1-22). Mahwah, NJ: Erlbaum.

Cromer, W. (1968). The effects of preorganizing reading material on two types of poor readers. Unpublished doctoral dissertation, Clark University.

DeStefano D., \& LeFevre, J. (2007). Cognitive load in hypertext reading: A review. Computers in Human Behaviour, 23, 1616-1641.

Dommes, A., Chevalier, A., \& Lia, S. (2011). The role of cognitive flexibility and vocabulary abilities of younger and older users in searching for information on the web. Applied Cognitive Psychology, 25, 717-726.

Eskey, D. E. (2005). Reading in a second language. In E. Hinkel (Ed.), Handbook of research in second language teaching and learning (pp. 563-580). Mahwah, NJ: Lawrence Erlbaum Associates, Inc.

Grabe, W. (1991). Current developments in second language reading research. TESOL Quarterly, 25, 375-406.

iMotion. (2013). Attention tool: Eye tracking standard license. Boston, MA: Eye Tracking A/S.

Just, M. A., \& Carpenter, P. A. (1976). Eye fixations and cognitive processes. Cognitive Psychology, 8, 441-480.

Foltz, P. W. (1993). Readers' comprehension and strategies in linear text and hypertext. 
Unpublished doctoral dissertation, University of Colorado, Boulder.

Elshair, H. M. (2002). The strategies used by students to read educational websites and their relation to website usability and text design. Unpublished doctoral dissertation, University of Pittsburgh, Pittsburgh, Pennsylvania.

Goodman, K. (1967). Reading: A psycholinguistic guessing game. Journal of The Reading Specialist, 6, 126-135.

Hill, R., Dickinson, A., Arnott, J., Gregor, P., \& McIver, L. (2011). Older web users' eye movements: Experience counts. Proceedings of the SIGCHI Conference on Human Factors in Computing Systems, Vancouver, BC, Canada, May 7-12,

Huang, H., Chern, C., \& Lin, C. (2009). EFL learners' use of online reading strategies and comprehension of texts: An exploratory study. Computers \& Education, 52, 1326.

Huang, Y. H. (2012). Designing task-oriented online reading activities: Taiwanese EFL students' experiences and views on online EFL reading activities. Proceedings of The Extensive Reading World Congress, 1, 4-7.

Kang, H., \& Gyorke, A. (2008). Rethinking distance learning activities: A comparison of transactional distance theory and activity theory. Open Learning, 23(3), 203-214.

Koda, K. (2005). Insights into second language reading: A cross-linguistic approach. New York, NY: Cambridge University Press.

Koda, K. (2010). The role of reading in fostering transcultural competence. Reading In A Foreign Language, 22(1), 5-10.

Leu, D. J., Kinzer, C. K., Coiro, J., \& Cammack, D. W. (2004). Toward a theory of new literacies emerging from the Internet and other Information and Communication Technologies. In R. B. Ruddell, \& N. J. Unrau (Eds.), Theoretical models and processes of reading (pp. 1570-1613). Newark, DE: International Reading Association.

Leu, D. J., Zawilinski, L., Castek, J., Banerjee, M., Housand, B., Liu, Y., \& O'Neil, M. (2007). What is new about the new literacies of online reading comprehension? In L. Rush, J. Eakle, \& A. Berger, (Eds.), Secondary school literacy: What research reveals for classroom practices (pp. 37-68). Urbana, IL: National Council of Teachers of English.

Maarof, N., \& Yaacob, R. (2011). Meaning-making in the first and second language: reading strategies of Malaysian students. Procedia - Social and Behavioral Sciences, 12, 211-223

Mayer, R. E. (1997). Multimedia learning: Are we asking the right questions? Educational Psychologist, 32, 1-19.

Miller, G. A. (1965). Some preliminaries to psycholinguistics. American Psychologist, 20, 15-20.

Norman, D. (2004). Emotional design: Why we love (or hate) everyday things. New York, NY: Basic Books.

Park, H., \& Kim, D. (2011). Reading-strategy use by English as a second language leaners in online reading tasks. Computers \& Education, 57, 2156-2166.

Rayner, K., \& Pollatsek, A. (1989). The psychology of reading. Englewood Cliffs, NJ: Prentice Hall.

Sakar, A., \& Ercetin, G. (2005). Effectiveness of hypermedia annotations for foreign language reading. Journal of Computer Assisted Learning, 21, 28-38. 
Salmeron, L., Kintsch, W., \& Canas, J. (2006). Reading strategies and prior knowledge in learning from hypertext. Memory and Cognition, 34, 1157-1171.

Singhal, M. (1999). The effects of reading strategy instruction on the reading comprehension, reading process and strategy use of adult SL readers. Unpublished doctoral dissertation, University of Arizona, Tucson.

Slaouti, D. (2002). The World Wide Web for academic purposes: Old study skills for new? English for Specific Purposes, 21(2), 105-124.

Smith, F. (1982). Understanding reading ( $3^{\text {rd }}$ ed.). New York, NY: Holt, Rinehart \& Winston.

Stanovich, K. (1991). Changing models of reading and reading acquisition. In L. Rieben \& C. Perfetti (Eds.), Learning to read: Basic research and its implications (pp. 1931). Hillsdale, NJ: Lawrence Erlbaum.

Sutherland-Smith, W. (2002). Weaving the literacy Web: Changes in reading from page to screen. The Reading Teacher, 55, 662-669.

Tractinsky, N., Cokhavi, A., Kirschenbaum, M., \& Sharfi, T. (2006). Evaluating the consistency of immediate aesthetic perceptions of web pages. International Journal of Human-Computer Studies, 64(11), 1071-1083.

Vandelanotte, C., Duncan, M., Plotnikoff, R., \& Mummery, W. (2012). Do participants’ preferences for mode of delivery (text, video, or both) influence the effectiveness of a Web-based physical activity intervention. Journal of Medical Internet Research, 14 (1), e37.

Warschauer, M. (1999, August). Millennialism and media: Language, literacy, and technology in the 21st century. Keynote address delivered at the World Congress of Applied Linguistics (AILA), Tokyo. Retrieved on June 19, 2013 from: http://vstevens.tripod.com/papyrus/16sep99a.htm.

Wilson, P., \& Anderson, R. C. (1986). What they don't know will hurt them: The role of prior knowledge in comprehension. In J. Orasanu (Ed.), Reading comprehension: From research to practice (pp. 31-48). Hillsdale, NJ: Lawrence Erlbaum.

Woolley, G. (2011). Reading comprehension: Assisting children with learning difficulties. New York, NY: Springer.

Yang, Y. (2010). Developing a reciprocal teaching/learning system for college remedial reading instruction. Computers \& Education, 55(3), 1193-1201.

Yang, S. C. (2001). Language learning on the World Wide Web: an investigation of EFL learners' attitude and perceptions. Journal of Educational Computing Research, 24(2), 155-181.

Yuill, N. M. \& Oakhill, J. V. (1991). Children's problems in text comprehension: An experimental investigation. Cambridge, UK: Cambridge University Press.

Zoghi, M., Mustapha, R., Rizan, N., \& Maasum, M. (2010). Looking into EFL Reading Comprehension. Procedia Social and Behavioral Sciences, 7, 439-445. 